\title{
The Phenomenology of Monologue Writing as Pedagogy
}

\author{
Scott Welsh
}

Victoria University

\begin{abstract}
This article explores the notion that for playwrights, actors, students of theatre or indeed anyone, the writing of monologues can be the catalyst for reflection on the nature of human existence, as well as an exercise in educational phenomenology. It also suggests that the playwright's processes, such as monologue writing, can be seen as a form of pedagogical practice and building on that, a form of public pedagogy.

The practice-led research drawn on in this article involves students participating in the process of monologue writing workshops conducted in two settings: in a secondary school with a group of drama students (nine students and two teachers), and in a university teacher-training setting (23 pre-service teachers). In the first setting the process was used to explore issues of social labelling, and in the second setting, the pre-service teachers were asked to consider the point of view of students from whom they felt a sense of disconnection. The creative process of writing monologues, traditionally confined to theatre practice and the drama classroom, was used with the aim of fostering empathy between the pre-service teachers and their students.
\end{abstract}

\section{Keywords}

monologue writing, pedagogy, theatre, drama studies, teacher training

Journal of Public Pedagogies, Number 1, 2016

Published by Public Pedagogies Institute: www.publicpedagogies.net.au Open Access article distributed under a CC-BY-NC 4.0 license

URL http://jpp.vu.edu.au/

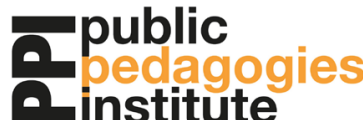


The relationship between public pedagogies and social theatre is clearly articulated by Brecht when he identifies the purpose of theatre to 'educate'-consciously, suggestively and descriptively (Willett 1978). Applied theatre in an educational setting is the ideal context in which to crystallise Brecht's vision regarding theatre and education by engaging a form of public pedagogy, because the primary focus of such environments is to learn. In this article, I will examine the potential for theatre practice to be applied to two educational settings: one school where students used monologue writing to explore social labels in their everyday life, and a university setting, where teachers-in-training created monologues with the aim of increasing empathy with their students. These settings enabled the intertwining of practice with pedagogy in a material way. I would argue that at its core, monologue writing is an exercise in educational phenomenology, and that this is central to both the practice of monologue writing and performance, as well as its theoretical conceptualisation. We are asking who we are, how we come to be who we are, and reflecting on the meaning of our experiences-how they are incorporated into our identity. When we ask these essential phenomenological questions in relation to others, the act of monologue writing and performance becomes an exploration of the empathy we feel for each other as fellow human beings.

I will aim to show that this form of reflective practice has the potential to be utilised as a pedagogical practice both inside and outside the classroom. I will draw on practice-based research conducted in two different educational settings that used a form of monologue writing called 'real fiction'-closely related to documentary theatre making-with an emphasis on exploring participants' real experience and speech in the writing of theatre pieces. In what follows, I draw heavily on Saldaña's (2005) notion of ethno-drama and consider myself to be working within a similar, though not identical, methodology. It is indeed my hope that the work I undertake as a practitioner and as an educational theorist, like Saldaña's, will '... capture verisimilitude and universality through their primary sources for monologue and dialogue: reality' (Saldaña 2005, p.3).

\section{Real Fiction Practice and Pedagogy}

I describe my theatre-making as 'real fiction' because, like many forms of artifice, it involves representing so-called 'reality' (Welsh 2014). In this instance, we conceive of reality as the patterns of speech or speech rhythms that identify individual ways of talking, our verbal method of expression. This is the 'reality' of the playwright. I call it 'real fiction' because when we, as writers, encounter the speech patterns of particular characters that take our fancy we are located neither in reality nor the fiction we are conceiving in that moment. This is a way of conceiving human existence, not merely for writers of plays and fiction. It also means, that social reality provides a wealth of resources from which to create characters.

Speech patterns of certain characters are encountered in social reality, in conversation, then extracted by the playwright and used to store and express particular knowledge about the world. For example, I have approached subjects such as mental health, criminal behaviour and school education, using this method. My research drawn on here, involved applying this method to a drama classroom by inviting student participants to engage in a workshop explaining and practising the playwriting method. Then, in an attempt to further this notion of real fiction as drama education, I conducted a monologue writing workshop with a group of student teachers.

In terms of public pedagogies, the use of drama or monologue-writing can be conceived as a public utterance and the utilisation of this practice in order to learn, coupled with the fact that the practice takes place in a drama classroom, consigns the work to the area of pedagogy. 
Ultimately, the work has the potential to question the way in which we think about learning and particularly drama education. The relationship between the terms 'drama education' and 'public pedagogy' are also strengthened by this practice because the drama classroom becomes a location where we not only learn about drama but we learn about the world, what we think about the world and how to talk about the world using the skills developed through drama practice.

There has been considerable interest in arts-based or arts-led pedagogies in some recent and historical literature, though it ought to be noted that theatre as education is a relatively new field. The importance the ancient Greeks placed on the social elements of theatre might have seen it elevated to the status of pedagogy, had it not been for the relative hostility of philosophy toward the poets. That being said, even Aristotle suspected there was something more than mere play to the practice of drama, dedicating an entire work to the subject of 'poetics'. The ancient Greeks certainly used drama and theatre educationally, however, over time the practice of the performing arts as a form of social or intellectual learning has been considerably marginalised (Brook 1972).

This is tempered with a more recent development, an entire movement of documentary-style drama, applied theatre and more particularly the use of ethno-drama has emerged. We can classify some performance practices themselves as pedagogical in nature, such as ethno-drama or documentary theatre, partly because the subject matter rather than the art-form is emphasised. For example, when we watch a performance like the Laramie Project-a piece of documentary theatre exploring a community's response to the fatal gay-bashing of a young man-we are not being immersed in a fantasy, we are learning, considering, contemplating (Kaufman, 2001). Such practices transcend the theatrical space and position themselves in their social surroundings.

We are once again viewing theatre as a study in its own right. For example, Tarquam McKenna, in his 'Seeing Beyond the Habitus', defines action methods in a therapeutic context as:

...the therapeutic field which reconceptualise the interests of our patients and clients where we employ rituals that can hold them to a defined, confined or refined in a place of being through enactment or performance (McKenna 2003, p.2).

McKenna claims that 'the embodiment of being and performance' ought to be viewed as 'ways of being and knowing', perhaps implying performance can be ontological and epistemological (McKenna 2003, p.2). He describes his methodology as performance, that is, an action method or practice-based research. I claim however, that sitting and writing real fiction in fact involves reflecting on our personal experience and our engagement with the world. It could be considered mere journal writing, were it not for our attempt to hear the voice of an 'other' in the writing process and document this 'hearing' in a performance context, whether that be a theatre or a drama classroom.

Communication theorist John Shotter, whose work is connected with philosophers Wittgenstein (1968) and Searle (1979), thoroughly explores practice-based methods of enquiry in his chapter 'Practice-Based Methods for Practitioners in Inquiring into the Continuous Co-emergent "stuff" of Everyday Life' (Shotter 2013), He identifies 'unfinished processes' and 'expressive realisations' that occur in the 'hurly-burly of everyday life' as opposed to the 'prepared conditions of the experimental laboratory...' (Shotter 2013, p.2). The work of contemporary Melbourne theatre-maker Lloyd Jones, for example, seems to involve a deliberate attempt to obliterate the 'prepared conditions' of the theatre comparable to Shotter's critique of the 'experimental laboratory' (Marshall 2002; Shotter 2013). In conventional theatre the 
audience seems to know what to expect, what will occur, how the experience will play out. There will be a prepared script presented by seasoned performers to an audience all of whom will sit in particular seatings and behave in particular ways. The work of artists such as Jones, disrupt this notion of theatre as a sterile laboratory, containing only the experimental scientists, technical experts focused on the task of creating theatre.

According to Searle, speech acts can be 'carved up' into various constituent parts that provide a wealth of social and psychological data, including the unique tones and rhythms of a person's speech (Searle 1979). The process of monologue writing introduces the practice of real fiction drama writing, or writing that uses speech rhythms drawn from social reality and experience. I would argue that my practice-based research in this area belongs to the category of ethno-drama (Saldaña 2005) or 'Reality Theatre' (Perry 2007), by involving 'real' participants in the process of making theatre. Like Saldana's work, my own research blurs the line between action-based sociological data collection and theatre. My work similarly aims to subvert what we mean by playwriting, and how we approach drama in the classroom, incorporating both the process of drama education and playwriting methodology.

The importance of lucid, vibrant and meaningful Arts practice in education is broadly recognised in contemporary drama education literature (Ewing, 2010). In his article exploring the potential of practice-led research Haseman, considering 'reflexive practice', makes this assessment:

The situations of practice-the complexity, uncertainty, instability, uniqueness and value conflicts... are increasingly perceived as central to the world of professional practice. These are practice-based research strategies and include: the reflective practitioner (embracing reflection-in-action and reflection-on-action); participant research; participatory research collaborative inquiry, and action research (Haseman 2006, p.3).

Haseman claims that 'these strategies re-interpret what is meant by 'an original contribution to knowledge.' They may not 'contribute to the intellectual or conceptual architecture of a discipline', however, according to Haseman, 'they are concerned with the improvement of practice, and new epistemologies of practice distilled from the insider's understandings of action in context' (Haseman 2006, p.3). What Haseman identifies is the place of arts-based and practice-based research, the distinguishing features of these practices and their location in the research landscape.

In addition to Haseman, Anne Harris and Christine Sinclair have identified the importance of critical play and creative processes in social and critical theory (Harris 2014; Sinclair 2009). Harris, for example, claims:

If we consider that the writing of the play is an act of inquiry (playwriting as method) then we can begin to see embodiment itself as methodology, a system of thought and set of tools (Harris 2014, p.12).

This notion of playwriting as methodology is pertinent to my study, and their privileging of the playwright's work and study of classroom culture intimately connects this research with my own. However while Harris insists on claiming the classroom represented in their work is fictional, I very deliberately use the term 'real fiction' to acknowledge both the active student contributions in the form of their writing and the passive contributions in terms of the surveys completed on-site (2014).

The practice-led methodology of my research deals directly with the notions of 'uncertainty', 'complexity', 'instability' and 'uniqueness', all of which are exciting for the creative practitioner but problematic in a research context. The reinterpretation of what constitutes 'research' is still a relatively new area. The research I conducted through monologue writing 
workshops and a dramatic play based on the findings, could be described as examples of 'transgressive' data, or at least a 'messy' methodology, similar to that of St. Pierre and her work in her home town as an insider/outsider (St. Pierre 1997; Ferguson \& Thomas-McLean 2009).

Practice-led methodology is distinguishable from practice-based methodology in that the former is work in which the 'main focus of the research is to advance knowledge about practice, or to advance knowledge within practice' ('Creativity \& Cognition,' authors unknown 2013). Alternately, practice-based research seeks to achieve an artifice, a play, painting or novel as the outcome and evidence of the research. The 'Creativity and Cognition Studios' define practice-based research as 'an original investigation undertaken in order to gain new knowledge partly by means of practice and the outcomes of that practice' (Creativity and Cognition Studios 2013). My work constitutes practice-led research because it advances knowledge about and within practice rather than by means of practice.

In my research I use the 'real fiction' monologue writing method, to focus on social labelling in the school environment. The vehicle of monologue allowed students to explore issues relating to social alienation, bullying and body image. Monologues were collected and conflated both to conceal the identity of the student participants and provide another layer to the research. That is, I had the opportunity as a playwright-researcher to elaborate on the students' ideas and further explore their potential as research. In the following extract for example, the student introduced the notion of body image and labelling and I have elaborated, gearing the discussion toward a philosophical contemplation of subjective and objective perceptions of reality:

Student 3: My brother calls me fat. He's a li'l shit. I get in trouble for calling him a li'l shit but how much damage is done by that compared to him calling me fat?!?! It's not his fault. He's nine. He probably doesn't even know what 'fat' is. Do I really know? Why does it hurt so much, being called 'fat'? I mean do I feel fat? Sometimes. Am I really fat, though? I look in the mirror at myself sometimes and I can hear a little voice in my head saying 'Fat, fat, fat...' and then I've got him in the background right behind me and just as the imaginary voice fades out, I hear the little shit and see him smirking behind me in the mirror. (Welsh 2016)

When conducted with teachers-in-training, this process of monologue writing based on speech rhythms and patterns was used to explore the issue of empathy between teachers and their students. The participants were asked to reflect on their recent experience in schools. After a brief discussion of the process and being shown an example of a monologue based on a real voice from conversational experience, they were invited to write a monologue based on the voice of a student with whom they least identified or with whom they felt the least amount of empathy.

Two examples of the monologues produced by the teacher-in-training sample group are reproduced below. 


\section{Example 1:}

This is shit!! Why the fuck are we reading a stupid fuckenn play that is so fucken old, that means nothing to me? BLAH fucken BLAH! Romeo sounds like a poof!

She just goes on this bitch. She looks at me like she knows better! She doesn't know me! No-one fucken knows me! Don't act like you care fucken bitch, you don't, I know it, you know it! STOP LOOKING AT ME!!!

OMG WTF can't she look at someone else?

I dunno, she wants a root hahaha! That'll fix her. Haha. I CBF with this shit. What's the point? Can we just watch the movie now? Then I can sleep! Didn't get much sleep last night. Or any night. WTF can't he just leave? Mum's f'n soft. He's fucken shit and fucken ugly. I'd kick him out, don't care if he 'pays the bills'. He's a f-wit. Don't look at me-I'm fucken reading!! Can't wait for the weekend, at least I can get out anyways. Jess better have some shit at her place, I can't be fucked goin home first. Thank fuck, she's got the movie! Oh he's hot! He's hot! Hahaha-this is better than the book, for sure.

(anon, teacher-in-training, personal communication monologue-writing data, 2015)

\section{Example 2:}

People, people, they think I'm stupid, not smart they think. He's dumb, they say. But they don't know man. They have no idea. I just can't say what I want to say the words they hard not easy to understand.

In my own language, I could be a smart person, very famous. But in English not much makes sense.

In my own language I could write anything I want to or I could say things to make them make sense to you.

(It is so frustrating) It makes me angry. I know what I want to speak, but nothing comes out good. My teachers, they correct me all the time.

I cannot speak good yet, Miss, give me time.

No one speaks this language at home. I have to teach my big brother but he is always busy, always tired. He gets angry too. But he is angry at all the people he goes to work with. They don't talk to him. They don't try. It is not fair, you know? We learn a whole new language and they don't even try.

And they think I am stupid.

(anon, teacher-in-training, personal communication monologue-writing data, 2015) 
These two examples illustrate the pedagogical potential in real fiction monologue writing. The first example exhibits the teacher attempting to foster empathy for their student and developing a complex emotional relationship with them, by attempting to inhabit their world through the monologue. In the second example, the teacher participant utilises monologue to explore cultural difference and language barriers to learning.

Two forms of learning are at work here. The first comes from practice: the actual process of writing the monologue creates realisations and revelations in the participant. The second is the knowledge contained in the monologue and the potential of the monologue to store and present qualitative data. In the first example, we go on a journey with the monologue creator from having no understanding or empathy for their student to coming to understanding and empathy through articulating the voice of the student. Whereas, the second monologue seems to begin with a hypothetical barrier to learning, for a student with English as a second language, expressed throughout the monologue. The author appears to have this idea in mind throughout the piece and uses the monologue to express it.

The process of writing of the monologues involved imagining the inner world of the student, helping to provide participants with greater insight into their student's perspectives, and resulted in participants reporting an increased feeling of empathy after participating in the process. Perhaps more significantly, though, the use of drama practice in the training of teachers found a whole new context. While these students were drama teachers in training, there appears to be no obvious reason why the process could not be used with teachers from other disciplines. The hypothesis of this work is that this need not be confined to drama educators or practitioners, but rather shows the potential for the public expression of drama as a form of pedagogy with broader applications.

To fully engage in the practice of theatre, it is necessary to open oneself to learning, exploring oneself through one's voice, and also exploring the world through the voice and experience of the other. In this article, I have explored the notion of public pedagogies through connections with examples of real fiction monologue writing, and have articulated moments in my research and practice as pedagogy. Whether it is expressed in the medium of a workshop with students and teachers, or inside the theatre in what we might call its 'original' form, this kind of theatre is a bringing together of practice and pedagogy. When we encounter it, we feel a certain discomfort because we know that we are blurring the lines between theatre practice and pedagogy. Inside classrooms, such as those described above, we are uncertain whether we are learning or creating and simultaneously questioning the very idea of education.

\section{References}

Archer-Hind, R. D. (Ed.), 1894, The Phaedo of Plato, Macmillan.

Brook, P 1972, The empty space, Penguin, Harmondsworth

Creativity and Cognition Studios, 2016, <http://www.creativityandcognition.com/ research/practice-based-research/differences-between-practice-based-and-practice-ledresearch> accessed 3-04-2016.

Dylan, B 1979, Slow Train Coming (recorded by Bob Dylan with Beckett \& Wexler). On Slow Train Coming, New York, Columbia Records, released August 20, 1979.

Ewing, R 2010, The Arts and Australian Education: Realising Potential. Professor Robyn Ewing, ACER Press, Melbourne 
Ferguson A, \& Thomas-McLean, R 2009, 'Messy Methodological Musings: Engaging in Successful Qualitative Health Research', Aporia 1: 4.

Harris, A. M. A 2014, Critical plays: embodied research for social change, Sense Publishers, Rotterdam

Haseman, B 2006, 'A Manifesto for Performative Research', Media International Australia incorporating Culture and Policy, theme issue 'Practice-led Research', 118, 98-106.

Kaufman, M. (2001). The Laramie Project: Alexandria, VA: Alexander Street Press.

Houle, C 1980, Continuing Learning in the Professions, Jossey-Bass, San Francisco

Lucas, D. W. 1968, Aristotle Poetics, Clarendon P

Marshall, J 2002, 'La Mama: Psycho-physical', Real Time Arts Issue 51 http://www. realtimearts.net/article/51/6888

McKenna, T 2003, 'Seeing Beyond the habitus-on action, art and healing', Inscape-Artcap November 13-16, Edith Cowan University Research Online.

Plato, 1980, The Symposium, Greek text with commentary by Kenneth Dover, Cambridge University Press, Cambridge

Saldaña, J 2005, Ethno-drama: An Anthology of Reality Theatre, Altamira Press, Walnut Creek, CA

Searle, J. R 1979, Expression and meaning : studies in the theory of speech acts, Cambridge University Press, Cambridge UK and New York

Sinclair, C 2009, Education in the arts: teaching and learning in the contemporary curriculum, Oxford University Press, Melbourne

St. Pierre, E.A. 1997, 'Methodology in the Fold and Irruption of Transgressive Data', International Journal of Qualitative Studies in Education, vol. 10, no. 2, pp. 175-89.

Taylor, P2002, 'Afterthought: Evaluating Applied Theatre', Applied Theatre Researcher, No.3. 1443-1726.

Willett, J 1978, Brecht on Theatre, Eyre Methuen, London

Wittgenstein, L., \& Anscombe, G. E. M. 1968, Philosophical Investigations (3rd edn. reprint of English text with index), Blackwell, Oxford

Welsh, S 2015, Charles Manson and the Subtle art of Radicalisation, performed at La Mama Theatre, <http://heyevent.com/event/d3mb7nh7kih26a/charles-manson-and-the-subtleart-of-radicalisation>, accessed 17-03-2016.

Welsh, S 2009, Barcode 30!!7 307, <https://realfiction333barcode.wordpress. com/2009/09/20/barcode-307-307/> acessed 19-03-2016.

Welsh, S 2014, 'Real Fiction: Theatre \& Creative Research',in B. Bolt (ed.), Material Inventions Applying Creative Arts Research, IB Taurus, London 


\section{About the Author}

Scott Welsh is a writer and thinker with a background in theatre, philosophy, and more recently drama and teacher education. He is performed playwright, a published poet and lover of philosophy. He believes that people come to education through experience, and that this is best expressed through the medium of theatre.

Dr. Scott Welsh

School of Education

Victoria University, Melbourne, Australia

Scott.Welsh@vu.edu.au 